\title{
TRABECULAR BONE REMODELING: AN EXPERIMENTAL MODEL
}

\author{
Steven A. Goldstej, Ph.D., Larky S. Matthews, M.D., Janet L. Kuhn, Ph.D. and Scott J. Hounster, Ph.D. \\ The Orthopaedic Research Laboratories. The University of Michigan, Section of Orthopaedic Surgery, Department of Surgery. \\ Ann Atbor. MI 48109, U.S.A.
}

\begin{abstract}
An experimental model, capable of inducing controlled stress fields to the distal femoral metaphyses of large dogs, is presented. This model utilized an implantable hydraulic device incorporating five loading cylinders and platens in direct contact with an exposed plane of trabecular bone. A microprocessor controls the loading characteristics, and finite element models were created to calculate the induced stress and strain fields. The trabecular remodeling response is measured using serial in vivo computed tomography, in vitro microcomputed tomography, and histologic analysis. The results of the experiment indicate that significant remodeling can be induced by the activated implant. An increase in trabecular orientation toward the loeded platens was observed. and a statistically significant decrease in connectivity was documented. The greatest effect was associated with a change in the loading rate. A fast rise time ( $70 \mathrm{~ms}$ ) loading waveform induced significant bone ingrowth at the implant interface when compared to a slow rise time waveform $(700 \mathrm{~ms})$, and demonstrated high correlations with the calculated stress fields as remodeling approached an equilibrium state.
\end{abstract}

\section{INTRODUCTION}

As described by Frost in the early 1960's (Frost, 1983; Frost, 1964), bone has been considered to remodel in discrete localized regions. The group of cells that participate in the remodeling process have been described as the bone multicellular unit (BMU) and initiate a controlled sequence of activation, resorption, and formation during which one quantum of bone is exchanged. Remodeling has been proposed to function as a method of preventing accumulation of fatigue damage and providing an adequate supply of relatively low mineral density bone to maintain mineral homeostasis (Frost, 1964; Parfitt, 1979; Parfitt, 1984). Parfitt (1984) extended the quantum theory of bone remodeling to include five steps; quiescence. activation, resorption, reversal, and formation. In addition. it has been theorized that it may be possible to proceed directly from activation to formation.

It is widely assumed that mechanical stresses influence the remodeling processes of bone and subsequently the structure and strength of bone, a consequence known as Wolff's law (Wolff, 1892). Although the basic concepts of Wolff's law have been generally accepted, the mathematical laws relating bone remodeling to stress, strain, or the mechano-biologic control systems which mediate these processes are unknown. Proposed controlling mechanisms have included: 1) microfatigue damage; 2) stress generated electrical potentials; 3 ) hydrostatic pressure on the extracellular fluids under load; and 4) alterations in cell membrane diffusion due to direct load (Binderman et al.,1988; Burr et al., 1985; Carter et al.,1987; Carter. 1982; Frost. 1983; Martin and Burr, 1982; Pollack et al.,1984; Pollard et al., 1984).

The majority of experimental studies in remodeling during the past 20 years have focused on cortical bone (Chamay and Tschantz, 1972; Goodship et al., 1979;
Hassler et al., 1974; Lanyon, 1979; Lanyon, 1987; Liskova and Hert, 1971; Rubin and Lanyon, 1984; Seireg and Kempke, 1969). Remodeling has been induced in animals through surgical modification of function, increase in activity or exercise, hypergravity, surgical reconstruction. and implantation or application of load delivery devices (Chamay and Tschantz, 1972; Churches el al., 1979; Goodship et al., 1979; Hassler et al., 1974; Hert et al., 1972; Klein-Nulend et al., 1987; Lanyon, 1979; Liskova and Hert, 1971; Lanyon, 1987; Pollard et al., 1984; Radin et al., 1972; Rubin and Lanyon, 1984; Seireg and Kempe. 1969). The results have lead to proposals of mechanisms ranging from stimulation of pacinian corpuscles in the periosteum, piezoclectricity, periostea//bone interface strain to microfatigue damage. Direct experimental stimulation of bone has also been performed in vitro in an effort to correlate biochemical or biophysical alterations with physical stimuli (Binderman et al.. 1988: Harell et al.. 1977: Rodan et al., 1975).

Perhaps the most significant work in cortical bone remodeling has been performed by Lanyon, Rubin, Goodship and co-workers. These studies have reported that the remodeling response is sensitive to four specific parameters: 1) peak strain magnitude; 2) the rate of strain change; 3) strain distribution; and 4) number of cycles per day. Their finding that only a few cycles (at the appropriate strain level) per day maintain bone structure (during their 8 week study) would suggest that remodeling can occur withour microfatiguedamage (Goodshipet al., 1979; Lanyon, 1979; Lanyon, 1974; Rubin and Lanyon, 1984). Although by utilizing in vivo strain gauges, they were able to correlate localized strain magnitude or strain rate to specific remodeling activity, they did not have the data to develop generalized strain or stress morphology relationships. Finally. Skerry et al. (1987) have provided evidence of a possible "strain memory" biologic remodeling transducer. 
Since the early observations that trabecular orientation and apparent density were functions of the magnitudes and directions of in vivo loads (Culmann et al.. 1866; VonMeyer, 1867; Wolff, 1892), (wo generalized theories have been proposed to account for the remodeling of trabecular architecture: trabecular orientation is a function of principal stress direction (trajectoral theory); and bone apparent density is a function of an effective stress measure. Only limited studies have dealt with trabecular bone remodeling experimentally. Lanyon demonstrated that in the sheep calcaneus. underlying trabeculi were aligned along principal strain directions measured from the cortex and hypothesized that this arrangement may reduce shear strains (Lanyon, 1974). A damage accumulation hypothesis has also been proposed to explain trabecular bone remodeling based on experimentally induced and clinically observed microfractures of trabeculi (Martin and Burr, 1982; Pollard et al., 1984; Radin et al., 1972).

Many investigations of bone remodeling. both trabecular and cortical, have been based on analytical models and solutions (Carter et al., 1987; Fyhrie and Carter, 1990; Cowin. 1986; Firoozbakhsh and Cowin, 1980; Hart et al., 1984: Hegedus and Cowin, 1976; Kimmel, 1986). The majority of these studies have been phenomenological in their approach, producing computational models and theoretical formulations which rely on functions or constants not yet experimentally determined. Hayes and Snyder, and Stone et al. have initiated the union between purcly analytical predictions and experimental observation, by presenting quantitative descriptions of the trajectoral theory and effective stress hypothesis (Hayes and Snyder, 1981; Stone ef al., 1984). While both these studies iended to support the trajectoral theory, conflicting relationships were found between Von Mises equivalent stress and bone density. This has been attributed to differences in finite clement modeling schemes, and to the open surface of the Von Mises failure criterion in three dimensional space (Fyhric and Caner, 1986). Both investigations emphasized the need for defining the in vivo experimental response of trabecular bone to known stress levels.

These two particular studies were also the first to incorporate stereologic measures of trabecular architecture into the problem of trabecular bone remodeling. Subsequent and continuing developments in methods to characterize the three-dimensional anisotropy of trabecular bone have further influenced mathematical stress morphology relationships (Cowin, 1985; Harrigan and Mann. 1984; Whitehouse. 1974). Cowin has proposed a relationship between stress and strain tensors and the fabric tensor (Cowin, 1985; Cowin. 1986). Fyhrie has studied the remodeling process with a perspective of structural optimization (Fyhrie and Carter, 1986; Fyhrie and Carter. 1990).

Finally, Cheal and coworkers (Cheal et al., 1985; Cheal et al. 1987) have presented the first studies designed to correlate stress morphology interactions during experimentally induced remodeling at an orthopaedic implant-bone interface. The results of these studies demonstrated that remodeling of trabecular bone adjacent to implants supports the concept of structural optimization. but the trajectoral theory in its simplest form was not applicable.

It is clear that trabecular bone responds to conditions which change its mechanical environment, such as total joint arthroplasty and fracture by altering its architecture and constitutive components. Likewise, architectural alteration in trabecular bone induced by metabolic or degenerative diseases and/or their treatments affects its mechanical integrity. Demineralization of trabecular bone and altered calcium homeostasis are documented consequences of prolonged exposure to reduced mechanical loads during micro-gravity space flight. It follows, therefore, that quantifying the adaptation of trabecular bone to mechanical stimulation may significantly influence our approach to many clinical conditions.

The purpose of this study was to develop an experimental model capable of determining the in vivo relationship between trabecular bone formation, resorption. orientation and implant induced stress. Specifically, this paper presents a description of the model and the results in a selected series of animals.

While the results of this study will benefit our understanding of the response of trabecular bone to total joint arthroplasty, it is hoped that they may also contribute significantly to studies related to mechanical or metabolic alterations in trabecular bone, as well as the mechanisms controlling remodeling.

\section{MATERIALS AND METHODS}

Our experimental model is based on an implant capable of delivering known loads to predetermined sites of trabecular bone in large, skeletally mature mongrel dogs. Predictions of the induced stress fields are calculated by a three dimensional finite element model and resultant remodeling is evaluated by quantitative computed tomography (CT), three dimensional microcomputed tomography, and histologic analysis.

\section{Implant Design and Implantation}

The implant consists of a single solid element with five. $6 \mathrm{~mm}$ bore hydraulic cylinders incorporated within its body. The cylinders have a common manifold and $5 \mathrm{~mm}$ loading platens attached to the distal end of each piston rod. The hydraulic fluid utilized in the implant is sterile saline.

As illustrated in Fig. 1, the main body of the implant is made from biocompatible stainless steel and the attachment plates from teflon. Each $5 \mathrm{~mm}$ diameter loading platen is porous coated to provide for a bony ingrowth interface. The platens, as well as the beaded surface, are made from commercially pure titanium providing a pore size from 180 to $450 \mu \mathrm{m}$. The implant is secured to the diaphysis of the bone with minimal compression across the base/bone interface using the teflon side plates as illustrated in Fig. 2. Control of the hydraulic pressure within the implants is provided by a microprocessor based servo 


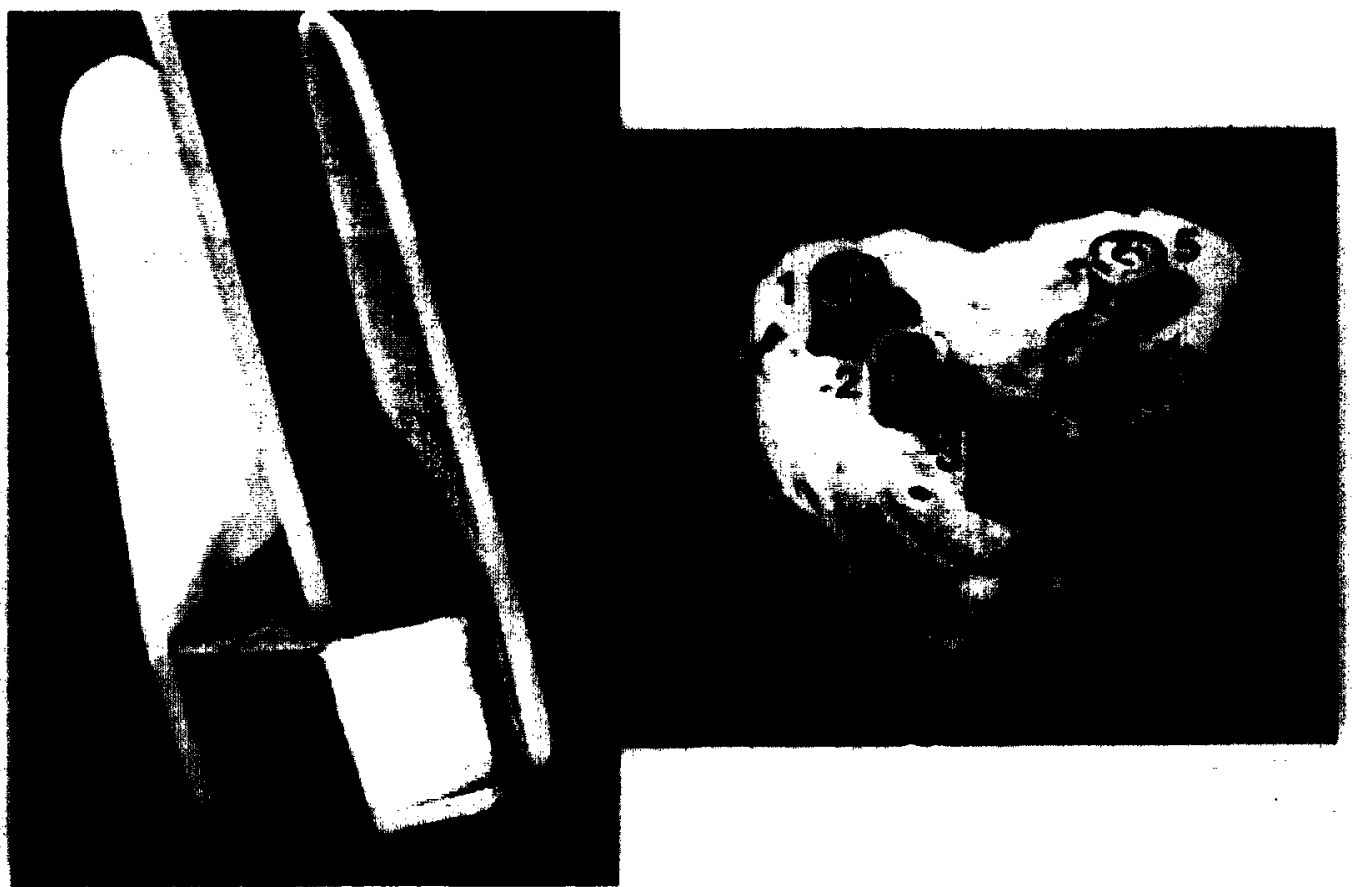

Fig. 1. (a) The hydraulic implant was made from biocompatible stainless steel and incorporated platens with a porous coating made from commercially pure titanium beads. (b) When the implant is removed at sacrifice, the five loading platens remain affixed to the femoral metaphyseal bone. The platen numbering schence is illustrated in the photograph.

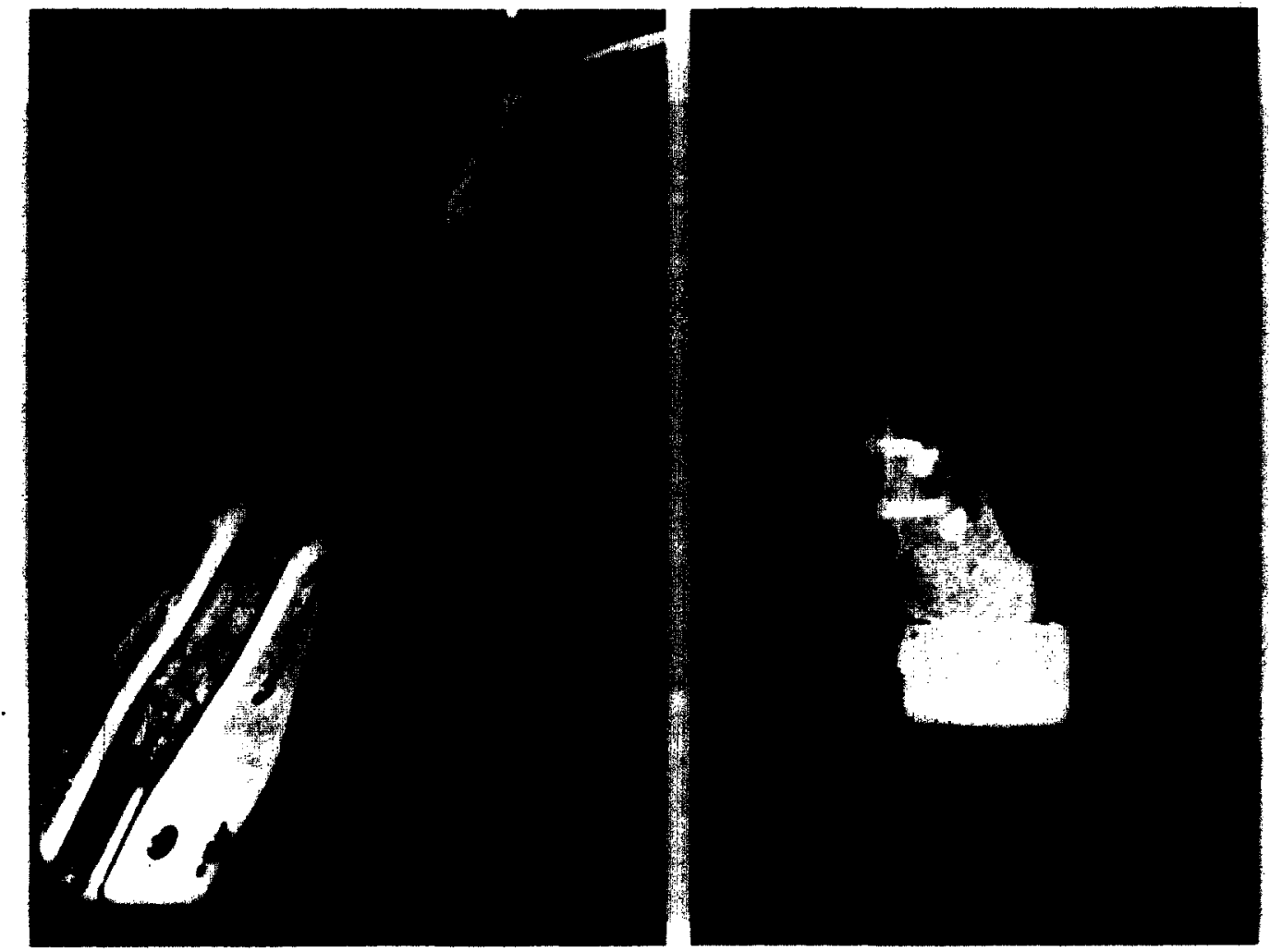

Fig. 2. (a) The hydraulic implant is affixed to the distal femur by teflon side plates screwed into the diaphysis. (b) As demonstrated in the radiograph. the hydraulic supply line is routed subcutaneously until it exits behind the animals neck. 

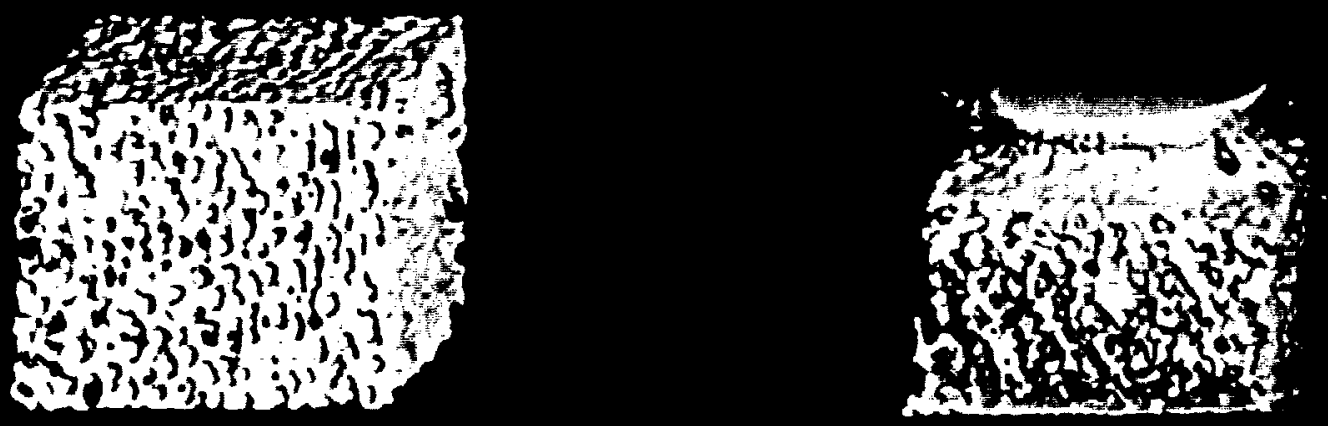

Fig. 6. The dramatic remodeling response of the trabecular bone to the squarcwave stimulation is demonstrated from this microcomputed tomography reconstruction of an experimental region and its matched contralateral volume. The high density material in the experimental specimen represents the "contcalided" bonce at the platen interface (platen 2. 38 weeks).

\section{Control}

\section{Experiment}
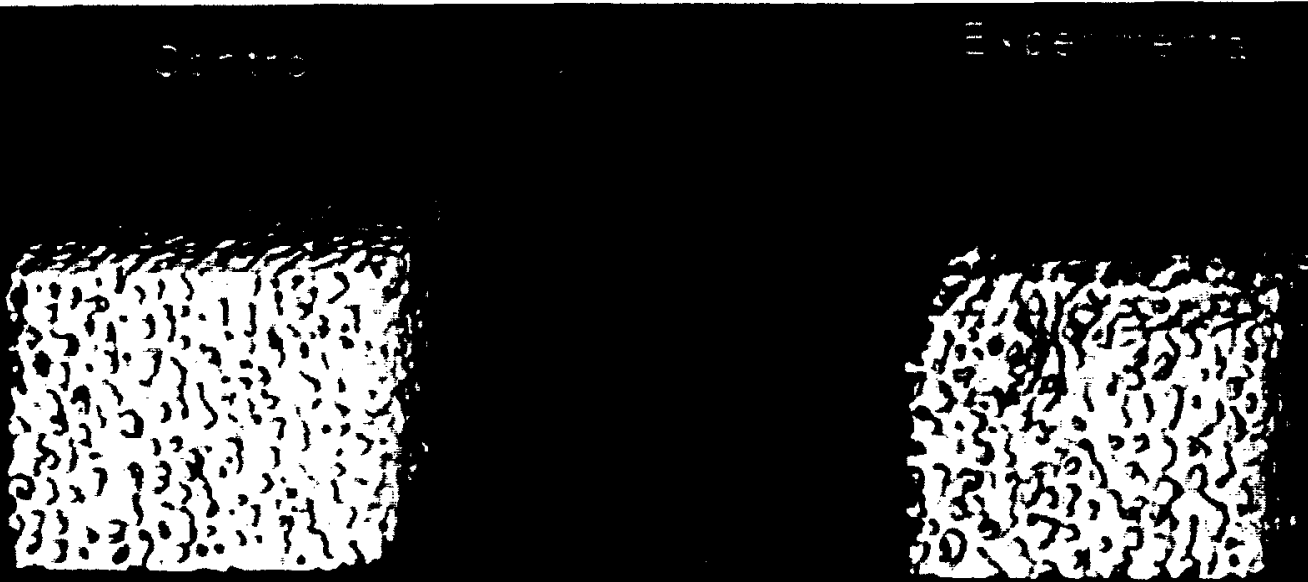

Fig. 7. The ramp waveform caused only moderate remodeling response in the trabecular bone adjacent to the loading platen. Little gross differences in architecture are observable between the experimental and matched contralateral regions (platen 2. 20 weeks). 

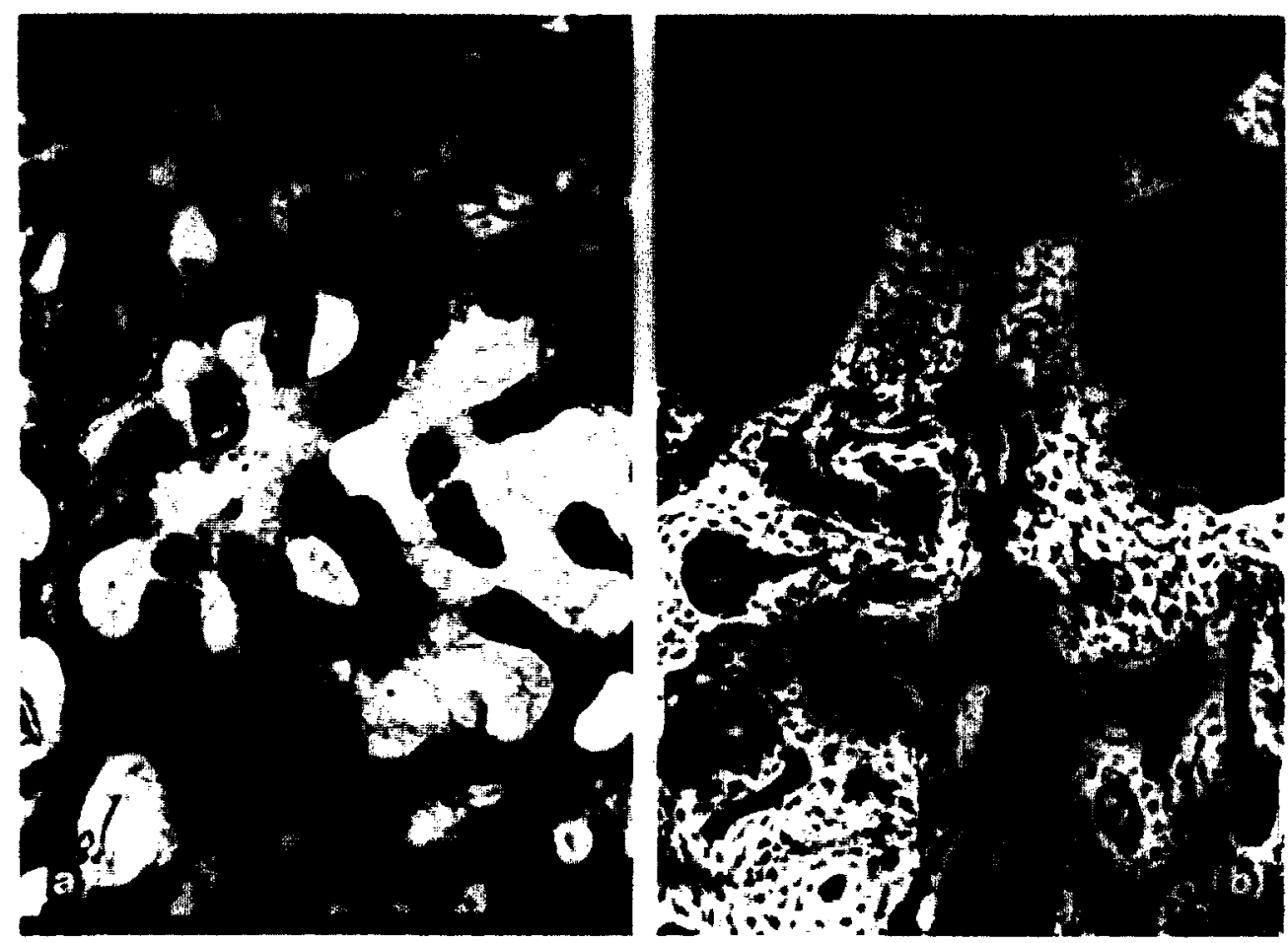

Fig. 8 . At 38 weeks (a) the response to the square waveform demonstrated significiant thickening of the tratecular bone with consistent ingrowth. At high magnification (b) the bone in the ingrowth region reflects continuing renodeling activity.
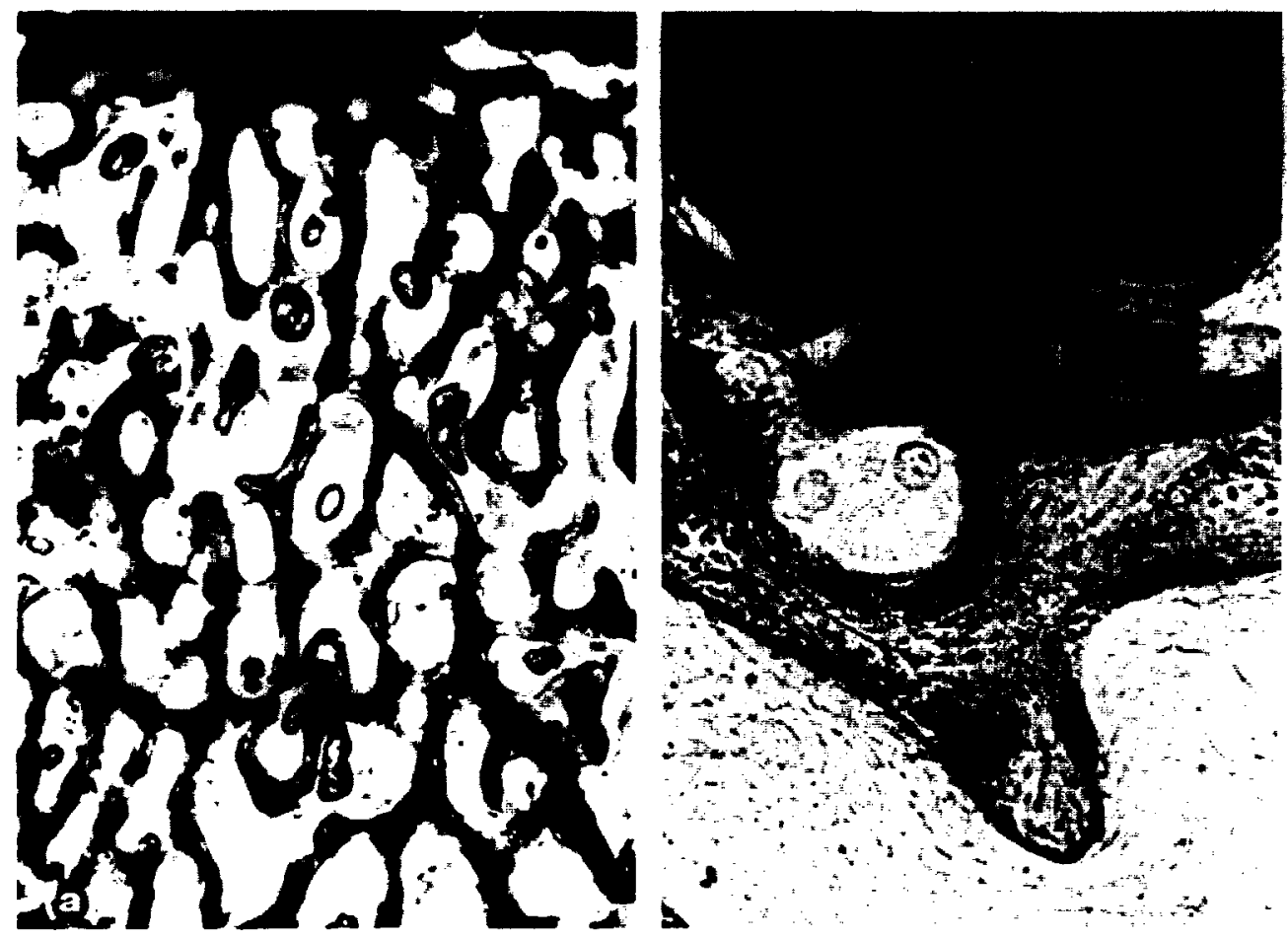

Fig. 9. Little response of the trabecular bone was observed under the ramp waveform stimulation (a). Al high magnification (b) both fibrous and bony tissue was observed in the ingrowth regions where the remodeling activity was quiescent. 

pump equipped with a pressure transducer (SETRA Model 250) feedback circuit.

After induction of anesthesia, the dogs are placed in the supine position. One preshaved limb is prepared with a betadyne scrub and draped free with surgical exposure of the knee. Maintaining sufficient soft tissue for stump coverage, the limb is amputated at the level of the knee, leaving the distal femur intact.

The distal femoral metaphysis is then osteotomized to expose a plane of trabecular bone. Using a series of specially designed and keyed templates, this surface of bone is "machined" flat and five, $1 \mathrm{~mm}$ deep, flat bottomed holes are milled into the bone to accept the five loading platens. All procedures are performed with constant saline irrigation to reduce deleterious thermal effects.

The teflon hydraulic fluid supply line is buried subcutaneously through the animal's back where it exits behind the neck. The tissue surrounding the line is sutured in place and a quick disconnect connector is attached. The implant is primed with the hydraulic fluid (saline) and tested for function. The implant is then covered completely with soft tissue including lower limb muscle to produce a clean and protected stump. A jacket is utilized to keep the dog from interfering with the hydraulic connector.

The advantage of using the hydraulic implant is that its force output is independent of the displacement of its pistons. Similarly, using this dynamic implant as an endoprosthesis ensures that the only loads on the metaphyseal bone result from the implant.

\section{Prediction of Stress Fields}

In order to determine the stress fields induced in the entire distal femoral metaphysis, a three dimensional finite element model has been developed. An example of the model is illustrated in Fig. 3.

A unique model was created for each animal in the study to account for variations in femur shape and relative implant position. The mesh is semi-automatically generated using the preprocessing software PATRAN (PDA Engineering, Costa Mesa, CA) and geometric boundary data gathered for each animal from computed tomography scans of the post surgical stump. The scans are performed on a General Electric $9800 \mathrm{CT} / \mathrm{T}$ scanner using bone reconstruction algorithms. Alignment of the scans are standardized by positioning the scan origin along a plane defined by four $1 / 16$ in. stainless steel beads visualized on the control console. The beads are implanted in the femoral diaphysis at the time of surgery in a plane $30 \mathrm{~mm}$ from the implant bone surface. The metaphysis is scanned at $1.5 \mathrm{~mm}$ increments and the data stored on magnetic tape until it is input into mesh generating software.

Two finite element models were created for each animal. The experimental limb was modeled using linear 8-node brick elements and the model for each animal contained 9075 degrees of freedom. The second finite element model was created to analyze the normal, intact femur. This model was also based on CT scans of the experimental metaphysis, but the anicular surface was
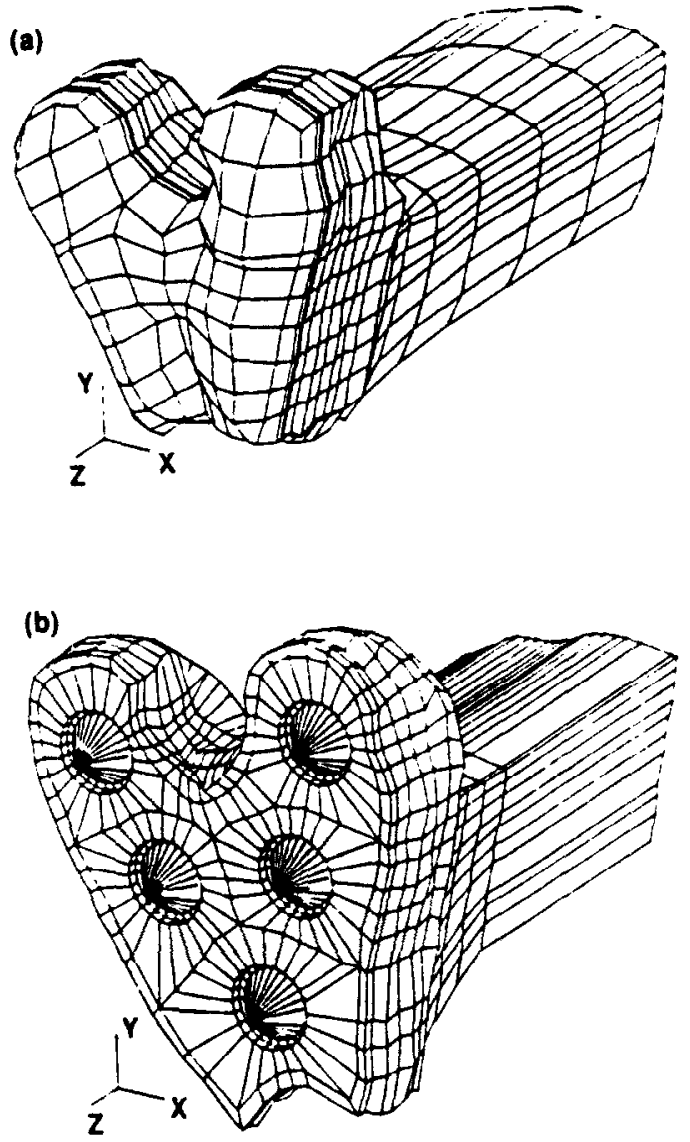

Fig. 3. The finite element models were created to reflect the specific geometry and implant location for each individual animal. The control model (a) includes the articular surface while the experimental model (b) includes the loading platens.

based on a histological analysis of a population of canine femurs. The mesh for the control analysis used 8-node brick elements, and each mesh contained 5280 degrees of freedom.

Analysis was performed for each of the animals corresponding to three time intervals. The first analysis was performed using the control femur model with material properties estimated from CT scans taken at the time of surgery. Normal joint loads were simulated based on a preliminary study of canine knee joint kinematics performed in our laboratory. Intact canine cadaver limbs were loaded in an Instron Materials test system (quasistatic) with the knee joint at $40^{\circ}$ of flexion. This position was assumed to be representative of a major component of canine gait as observed by us for animals running on a treadmill. The resultant contact pressure distribution in the tibial-femoral as well as patella-femoral joints were measured using Fuji pressure sensitive film. Data was acquired for loads of $300 \mathrm{~N}$ (1 canine weight) placed across the hip joint as was consistent with canine gait data (Heck, 1988).

The second analysis was performed using the experimental femur model. The loading was based on the 
experimental pressures of the implant and the material properies were estimated from CT densities. This analysis allowed estimation of stress distributions in the normal trabecular bone architecture due to the experimental implant immediately after the surgical procedure. The third analysis was the same as the second analysis except that the material properties were estimated from CT scans taken after each animal was sacrificed. Experimental relationships between modulus and CT determined density were derived from a sample of 15 normal canine femurs which were sectioned into $8 \mathrm{~mm}$ cubes of trabecular bone with their axes aligned along the anatomic axes of interior/ superior, anterior/posterior, and medial/ateral. Each specimen, after CT scanning, was tested in three orthogonal directions to preyield and then in one randomly chosen direction to failure. Correlations between the mean moduli and ash weight density and between CT density and ash weight were determined. The regression equations utilized to estimate the material properties were:

$$
\begin{aligned}
\text { Ash weight } & =0.162+3.83 \times 10^{-4} C T \quad\left(r^{2}=0.69\right) \\
E_{\text {mean }} & =1352.9(\text { Ash weightr })^{1.48} \quad\left(r^{2}=0.78\right)
\end{aligned}
$$

The trabecular bone was assumed to be heterogenous isotropic with a Poisson's ratio of 0.2 . The three analyses allowed prediction of stress distributions for normal gait, initial experimental loading, and final experimental loading. All analyses were performed using the MARC finite element code (MARC analysis, Palo Alto, CA).

Three techniques are utilized to quantify the induced changes in the femoral metaphyseal bone: computed tomography, microcomputed tomography, and histologic analysis.

\section{Computed Tomography}

Tomography was performed on each animal at implant activation, two, four, or six week intervals, and at sacrifice. Scanning was accomplished using a General Electric 9800 CT/T scanner. The limb was positioned in the scanner using a plexiglass holding fix ture and the scan sequence was aligned along a plane defined by four stainless steel markers placed in the diaphysis of the bone at the time of surgery. $1.5 \mathrm{~mm}$ thick, consecutive slices were acquired for the entire metaphyseal region. A calibration phantom consisting of five concentrations of potassium diphosphate solution was positioned to be in each scan slice. Using this detailed protocol, serial scans of matched slices of metaphyseal bone could be made throughout the course of the experiment. The coefficient of variation of repeated placement in the scanner for the same volume was between 3 and $9 \%$.

As previously described, the initial scans were utilized to create the geometrically correct finite element model for each animal. These same finite element mesh planes were then used to segment the scan data into regions of interest corresponding to specific elements. For each region of interest defined by the finite element mesh template, the average CT densities were determined and stored in analysis files. Changes in density corresponding to each finite element region of interest could be documented as a function of implant load characteristics and time.

\section{Microcompused Tomography}

The remainder of experimental variables were determined after sacrifice of the animals. At sacrifice, the implants were carefully removed leaving the five loading platens still fixed to the bone surface. Both femurs (experimental and contralateral control) were dissected free of soft tissue and their proximal ends embedded in an aluminum block using Velmix stone (Kerr, Romulus, MI.). Each metaphysis was then sectioned into $8 \mathrm{~mm}$ cubes of trabecular bone. The most distal level of bone in the experimental side was sectioned to produce five specimens, each with the loading platens centralized on the surface of the cubes. The anatomically corresponding regions were sectioned from the control metaphysis. All sectioning was performed on a numerically controlled milling machine under constant irrigation. Specimens were kept moist at all times and frozen at $-20^{\circ} \mathrm{C}$ in sealed containers between protocols.

Each cubic specimen of bone was scanned on a developmental microcomputed tomography scanner initially developed at the scientific research laboratory of Ford Motor Company. The system provides complete three dimensional digitization of the specimens with an approximate resolution of $50 \mu \mathrm{m}$ (Feldkamp el al., 1989). From the three dimensional data set, the following morphologic and architectural variables were calculated: mean trabecular plate thickness $(\mu \mathrm{m})$, mean trabecular plate number, mean trabecular plate separation $(\mu \mathrm{m})$, bone volume fraction (percent), surface to volume ratio $\left(\mu \mathrm{m}^{-1}\right)$, connectivity (Euler-Poncaire number), and degree of orientation (percent). These variables can be calculated for the entire bone volume or any subvolume. A complete description of the microcomputed tomography scanner and the derivation of the measurement algorithms can be found elsewhere (Feldkamp er al., 1989, Kuhn et al., 1990).

\section{Histologic Analysis}

The five trabecular volumes with attached loading platens from each experimental femur were fixed in $70 \%$ ethanol, dehydrated, prestained in Osteochrome, infiltrated and embedded in methyl methacrylate. $150 \mu \mathrm{m}$ sections were prepared using a diamond saw and ground to approximately $75 \mu \mathrm{m}$ for histologic analysis. The histologic evaluation included characterization of the tissue structure and calculation of the quantity and quality of tissue ingrowth using a semi-automatic image processing system.

\section{EXPERIMENTAL DESICN}

The results of nine experimental animals will be presented in this paper. These animals were chosen to represent the response of trabecular bone to a variety of alterations in the mechanical environment induced by the implant. The purpose was to verify the effectiveness of the model while 
beginning to establish some preliminary stress morphology correlations at an implant bone interface.

Table I presents the experimental conditions. The dogs were subjected to implant loads of 50,60 and $80 \mathrm{~N}$ per platen at $0.5 \mathrm{~Hz}$ frequency for $1 \mathrm{~h} / \mathrm{day}$ ( 1800 cycles). Sacrifice times ranged from 4 to 38 weeks. Two specific waveforms were utilized: a fast rise time or nearly square waveform (70 ms rise time), and a slower ramp waveform (700 ms rise time) (Fig. 4).

\section{RESULTS}

After sacrifice of the animals, the implants were carefully removed and examined. There was no evidence of inflammatory response, but in three of the animals there was a mild discoloration of several loading platens at the interface between the platens and piston rods. The design of the implants allows removal of the main body leaving the platens fixed to the bone without disturbing the interface. In general, all loading platens in these animals were qualitatively well attached to the bone surface.

Each implant was activated at the lab bench postremoval to ensure that they were functioning correctly at the time of sacrifice. All devices behaved according to design.

In all femurs there was an approximately $1 \mathrm{~mm}$ thick fibrous tissue layer interposed between the implant and the bone in the regions between the platens.

The serial computed tomography analysis revealed the first evidence of variability in the trabecular bone response. In general, the density of the bone below the platenbone interface ( $3 \mathrm{~mm}$ thick, $5 \mathrm{~mm}$ diameter volume located $2 \mathrm{~mm}$ from platen surface) changed very little from 0 to 20 weeks of loading in the ramp waveform cases. In contrast, significant perturbations in density were found with the fast rise time stimulation (Fig. 5). These results seemed to suggest that only the square wave animals were undergoing significant remodeling processes.

In order to statistically evaluate the results of our remodeling experiment to date, a general linear model

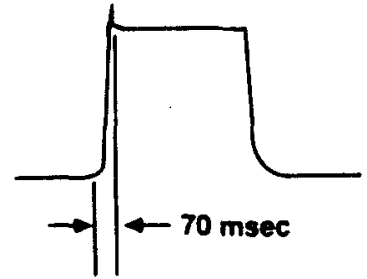

Square waveform

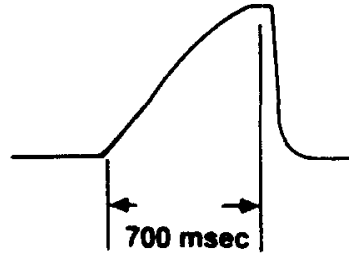

Ramp wavetorm
Fig. 4. Two characteristic waveforms were used in the study: a fast rise time (70 ms) and slow rise time $(700 \mathrm{~ms})$ condition.

(unbalanced analysis of variance) was fitted to each of the dependent variables from microcomputed tomography images of trabecular bone cube specimens (mean irabecular plate thickness, mean trabecular plate number, mean trabecular plate separation. connectivity per volume. bone volume fraction. surface to volume ratio. connectivity. and degree of orientation). The independent factors were loading magnitude, waveform characteristics, and time (weeks). Three models were fitted to the data:

(1) A model of main effects.

(2) A model of main effects augmented by the waveform characteristics, and time which were estimated from balanced subsets of the experiments.

(3) An all inclusive model including all interactions with variables to account for bone cube specimen type (experimental bone, contralateral matched region of bone).

These analyses were performed for the five platen locations and patterns of results across locations were identified. The statistical analysis was nun on the software package marketed by SAS. Inc. Table 2 presents the experimental data from all platen locations in all experimental animals. The statistical significance of the data was interpreted in reference to measures of micro CT reliability as well as the adequacy of using the contralateral femur as a control. Details of these measures can be found in the papers of Kuhn et al. (1990, 1990a).

Table I. Experimental parameters

\begin{tabular}{cccccc}
\hline Dog ID & $\begin{array}{c}\text { Frequency } \\
(\mathbf{H z})\end{array}$ & Waveform & $\begin{array}{c}\text { Cycles } \\
\text { (per day) }\end{array}$ & $\begin{array}{c}\text { Magnitude } \\
(\mathbf{N})\end{array}$ & $\begin{array}{c}\text { Approx. } \\
\text { sacrifice } \\
\text { time (wk) }\end{array}$ \\
\hline 4 & 0.5 & $S$ & 1800 & 60 & 4 \\
3 & 0.5 & $S$ & 1800 & 60 & 10 \\
5 & 0.5 & $S$ & 1800 & 60 & 20 \\
9 & 0.5 & $S$ & 1800 & 80 & 10 \\
12 & 0.5 & $S$ & 1800 & 80 & 17 \\
10 & 0.5 & $S$ & 1800 & 80 & 38 \\
16 & 0.5 & $R$ & 1800 & 50 & 4 \\
15 & 0.5 & $R$ & 1800 & 50 & 10 \\
17 & 0.5 & $R$ & 1800 & 50 & 20 \\
\hline
\end{tabular}

$S$ - square waveform (70 ms rise time)

$R$ - ramp waveform ( $700 \mathrm{~ms}$ rise time) 


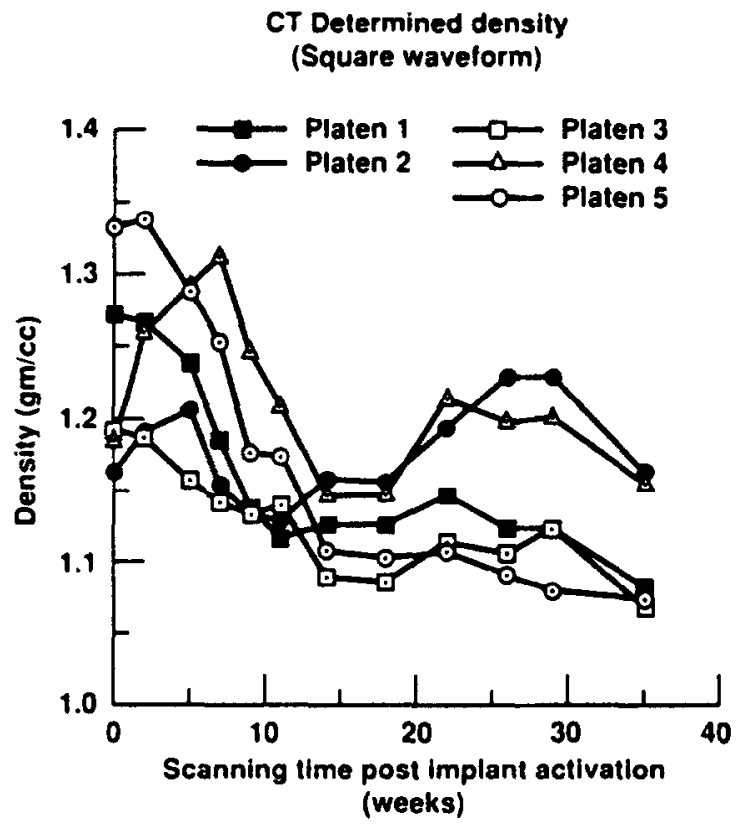

CT Determined density (Ramp waveform)

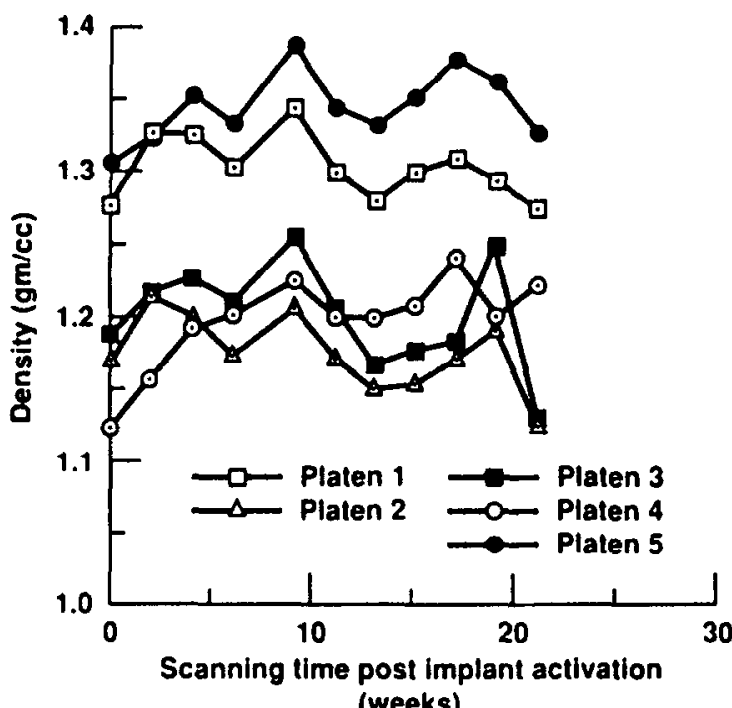

Fig. 5. An example of the pattern of computed tomography determined densities for two long term animals are illustrated as a function of time. The densities were determined for a $3 \mathrm{~mm}$ volume of bone just beneath the platens in a square waveform (a) and ramp waveform (b) animal.

Perhaps the first most important finding was that a significant amount of the remodeling response occurred in a localized region near the bone platen interface. This finding, which is consistent with previous clinical and experimental implant analyses, is also consistent with the regional accelerated phemomena (RAP) described by Frost (1983). The contribution or the intensity of the RAP phenomena was strongly interacted, however, with characteristics of the waveform. Analysis of the trabecular bone regions subjected to squarewave loading, between 10 and 38 weeks, demonstrated a unique remodeling pattem as illustrated by the results of microcomputed tomography (Fig. 6) at 38 weeks. The response was very localized to within $5 \mathrm{~mm}$ of the loading platen and was characterized by a "corticalization" of the bone in the ingrowth and adjacent regions. In contrast to this, the results from bony regions subjected to the ramp waveform. at 10 to 20 weeks, demonstrated a much reduced remodeling response (Fig. 7).

Ingrowth was expressed as a function of potential ingrowth volume and location. The most significant results were found from a comparison of the ingrowth to the squarewave, or fast rise time and the ramp, or slow rise time loading characteristics at ten weeks and greater. Squarewave specimens were characterized by dense. thick trabeculae and a mass of almost solid bone overlying the platens. Ingrowth was common and often extended across the majority of the platen and through the porous surface to the underlying substrate (Fig. 8). In general, the trabeculae appeared to be oriented vertically and radiating away from the loading surface. At higher magnification, the bone was seen to be both lamellar and woven, and possibly undergoing continuing rapid remodeling as demonstrated by irregular surfaces with rough scalloped edges and abundant howships lacunae (Fig. 8). In contrast, specimens from the ramp loaded platens demonstrated less ingrowth penetration and were characterized by thin sparse trabeculae with large open spaces between trabeculae. In general, these sections contained a single horizontally oriented trabeculac or plate-like sinucture immediately adjacent to the loading platen. At higher magnification, the trabeculae were lamellar, had smooth surfaces, and appeared to be relatively quiescent (Fig. 9).

Quantitative ingrowth analysis revealed a consistent profile of ingrowth penetration for the squarewave animals. While the deepest penetration of ingrowth occurred in the very centralized regions of the platen, ingrowth near the periphery was observed less often (Fig. 10) .

In contrast, the profile of ingrowth for the ramp animals was much more inconsistent. These findings lead us to hypothesize that the extent and profiles of bony ingrowth seem to be dependent on the character of the stress transmitted at the bone implant interface once it exceeds some stimulus threshold (rate sensitive threshold in this study). However, below this threshold, the amount and profile of ingrowth may be more significantly influenced by the fracture like physiologic response of the tissue to the surgical trauma. The details of the ingrowth analysis and correlations with characteristics of the stimuli will be presented elsewhere.

As a result of the statistical analysis, (analysis of variance and multiple regression models) the following statistically significant relationships were found:

(1) There was a significant relationship between the porous ingrowth and the loading characteristics at ten weeks post surgery and greater. In a preliminary analysis of the ingrowth sections, the squarewave loaded animals demonstrated a significantly greater area of bony ingrowth when compared to the ramp waveform animals ( $p<0.05$ ). 
Table 2. Percent change in trabecular morphology and anisocropy for the experimental animals is illustrated. Daca are expressed as (control - experimental) $/($ control $) \times 100$

Note: The bone specimen from dog 3 (platen 4) was damaged during processing and unavailable for analysis.

\begin{tabular}{|c|c|c|c|c|c|c|c|c|c|c|}
\hline Dog & Platen & $\begin{array}{l}\text { Wave- } \\
\text { form }\end{array}$ & Weeks & Conn & BVF & SV & TPT & TPN & TPS & $\begin{array}{l}\text { Deg } \\
\text { orient }\end{array}$ \\
\hline 4 & 1 & $\mathbf{S}$ & 4 & -42.29 & 1.82 & -9.50 & 7.89 & -6.42 & 4.95 & 16.78 \\
\hline 4 & 2 & $\mathbf{S}$ & 4 & 10.38 & -9.54 & -3.81 & 3.34 & -13.63 & 16.29 & 8.13 \\
\hline 4 & 3 & $\mathbf{S}$ & 4 & -2.61 & -4.15 & 2.54 & -2.30 & -1.36 & 4.30 & 4.31 \\
\hline 4 & 4 & $\mathbf{S}$ & 4 & 16.93 & -41.90 & -14.87 & 12.82 & -63.45 & 47.98 & 12.79 \\
\hline 4 & 5 & $\mathbf{S}$ & 4 & -38.14 & -2.58 & 5.04 & -4.41 & 2.23 & 0.17 & 16.62 \\
\hline 3 & 1 & $\mathbf{S}$ & 10 & -54.07 & 4.97 & -0.01 & 0.61 & 5.43 & -7.93 & 25.97 \\
\hline 3 & 2 & $\mathbf{S}$ & 10 & 15.67 & -16.28 & 2.20 & -2.58 & -13.01 & 17.72 & 18.08 \\
\hline 3 & 3 & $\mathbf{S}$ & 10 & -69.22 & 22.05 & -14.43 & 12.10 & 11.35 & -26.21 & 15.09 \\
\hline 3 & 5 & $S$ & 10 & -58.05 & 25.11 & 0.72 & 0.13 & 25.28 & -55.55 & 6.04 \\
\hline 5 & 1 & $\mathbf{S}$ & 20 & -32.84 & -8.38 & 19.60 & -24.74 & 13.25 & -8.37 & 4.62 \\
\hline 5 & 2 & $\mathbf{S}$ & 20 & -23.72 & -46.11 & 29.68 & -45.51 & -0.95 & 20.59 & 5.58 \\
\hline 5 & 3 & $\mathbf{S}$ & 20 & -26.02 & 28.10 & -16.06 & 12.19 & 19.06 & -42.16 & 12.54 \\
\hline 5 & 4 & $\mathbf{S}$ & 20 & 52.77 & -36.26 & 10.42 & -12.54 & -21.52 & 29.35 & -0.29 \\
\hline 5 & 5 & $\mathbf{S}$ & 20 & -1.02 & 20.94 & -7.63 & 7.02 & 16.11 & -41.63 & 27.45 \\
\hline 9 & 1 & $\mathbf{S}$ & 10 & -40.83 & -33.53 & 32.90 & -51.00 & 11.15 & 15.77 & 14.41 \\
\hline 9 & 2 & $\mathbf{S}$ & 10 & -9.52 & -68.06 & 34.80 & -54.73 & -9.30 & 36.85 & 0.34 \\
\hline 9 & 3 & $\mathbf{S}$ & 10 & -54.64 & -0.47 & 16.46 & -21.32 & 16.62 & -21.01 & -14.60 \\
\hline 9 & 4 & $\mathbf{S}$ & 10 & -1.64 & -64.45 & 28.12 & -39.48 & -18.28 & 37.78 & -10.64 \\
\hline 9 & 5 & $\mathbf{S}$ & 10 & -4.61 & -3.95 & 13.23 & -14.22 & 9.59 & -5.63 & 11.35 \\
\hline 12 & 5 & $\mathbf{S}$ & 17 & -73.63 & 29.42 & 9.70 & -13.11 & 37.57 & -107.85 & 10.46 \\
\hline 12 & 4 & $\mathbf{S}$ & 17 & -36.67 & -16.35 & 22.28 & -30.30 & 10.28 & -5.33 & 7.53 \\
\hline 12 & 3 & $\mathbf{S}$ & 17 & -51.45 & -2.86 & 15.51 & -22.84 & 15.44 & -16.31 & 2.90 \\
\hline 12 & 2 & $\mathbf{S}$ & 17 & -53.44 & -8.66 & 25.51 & -35.18 & 19.33 & -19.13 & -3.31 \\
\hline 12 & 1 & $\mathbf{S}$ & 17 & -64.34 & 21.97 & 4.52 & -5.51 & 26.62 & -60.76 & 13.61 \\
\hline 10 & 1 & $\mathbf{S}$ & 37 & -62.20 & 44.14 & -23.11 & 18.93 & 32.09 & -90.37 & 15.73 \\
\hline 10 & 2 & $\mathbf{S}$ & 37 & -5.81 & 10.15 & -9.83 & 8.84 & 1.06 & -5.21 & 1.56 \\
\hline 10 & 3 & $\mathbf{S}$ & 37 & -27.70 & 28.00 & -25.73 & 19.39 & 10.53 & -27.89 & -17.48 \\
\hline 10 & 4 & $\mathbf{S}$ & 37 & -22.52 & -16.90 & 12.32 & -15.60 & -1.19 & 7.59 & -2.03 \\
\hline 10 & 5 & $\mathbf{S}$ & 37 & -73.08 & 61.31 & -45.86 & 32.10 & 43.90 & -175.73 & 23.50 \\
\hline 16 & 1 & $\mathbf{R}$ & 4 & -17.30 & 28.63 & -22.81 & 18.48 & 12.75 & -43.76 & 5.20 \\
\hline 16 & 2 & $\mathbf{R}$ & 4 & -26.22 & -22.40 & 14.71 & -18.04 & -2.90 & 8.91 & -16.86 \\
\hline 16 & 3 & $\mathbf{R}$ & 4 & 35.47 & -24.32 & 2.51 & -3.11 & -20.70 & 24.18 & 0.61 \\
\hline 16 & 4 & $\mathbf{R}$ & 4 & -46.02 & 25.06 & -9.13 & 7.17 & 19.81 & -38.70 & -0.47 \\
\hline 16 & 5 & $\mathbf{R}$ & 4 & -50.21 & 36.07 & -20.13 & 16.21 & 23.47 & -74.71 & -13.20 \\
\hline 15 & 1 & $\mathbf{R}$ & 10 & -49.84 & 29.62 & -19.19 & 15.18 & 16.55 & -70.90 & -13.95 \\
\hline 15 & 2 & $\mathbf{R}$ & 10 & -48.36 & -30.46 & 27.29 & -39.52 & 6.14 & 6.90 & -23.24 \\
\hline 15 & 3 & $\mathbf{R}$ & 10 & -51.60 & -17.33 & 21.20 & -27.13 & 7.97 & 1.04 & -9.63 \\
\hline 15 & 4 & $\mathbf{R}$ & 10 & -56.83 & 5.81 & 10.91 & -18.75 & 19.32 & -27.82 & 4.22 \\
\hline 15 & 5 & $\mathbf{R}$ & 10 & 2.43 & -17.80 & 12.43 & -14.42 & -2.82 & 18.29 & 9.12 \\
\hline 17 & 1 & $\mathbf{R}$ & 20 & -29.48 & 17.63 & -8.08 & 6.94 & 11.23 & -41.82 & -3.79 \\
\hline 17 & 2 & $\mathbf{R}$ & 20 & -41.89 & 9.16 & 5.35 & -5.99 & 14.25 & -23.19 & 0.03 \\
\hline 17 & 3 & $\mathbf{R}$ & 20 & 17.79 & 10.72 & -11.47 & 10.20 & 0.38 & -12.86 & -16.30 \\
\hline 17 & 4 & $\mathbf{R}$ & 20 & -48.43 & 2.05 & 13.00 & -15.66 & 15.25 & -19.71 & -3.34 \\
\hline 17 & 5 & $\mathbf{R}$ & 20 & -30.54 & 13.56 & -0.78 & -0.09 & 13.82 & -35.57 & 6.58 \\
\hline
\end{tabular}

$$
\begin{gathered}
\text { Waveform } \\
\text { S - square } \\
\text { R - ramp }
\end{gathered}
$$

Conn - connectivity

BVF - bone volume fraction
SV - surface to volume ratio

TPT - trabecular plate thickness

TPS - trabecular plate separation

TPN - trabecular plate number

Deg orient - degree of orientation 


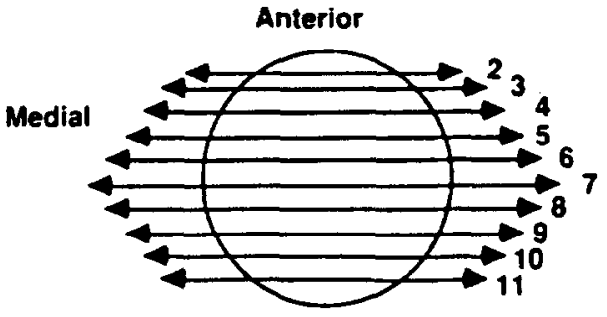

Ptaten histologic sectioning, reterence

Ingrowth data for platen *2 (Pooled dogs 10-38 weeks)

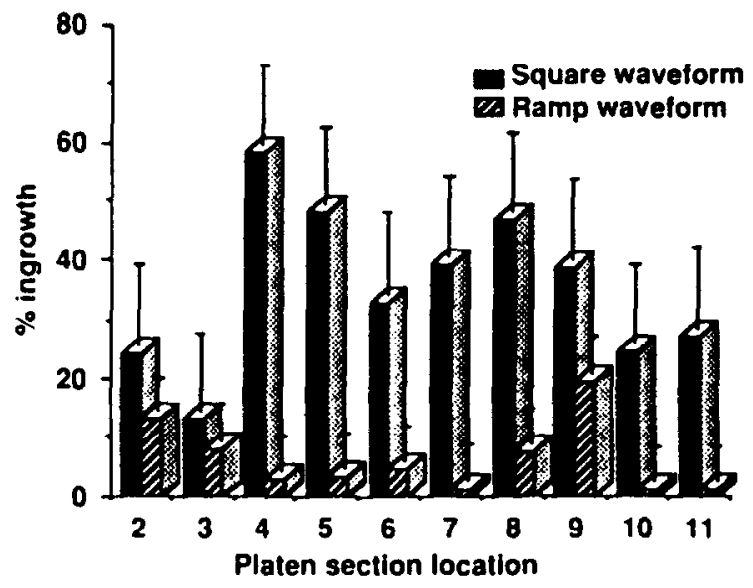

Fig. 10. To illustrate the general pattern of ingrowth. the distribution of tissue incorporation (expressed as a percent of available space) is presented for one platen location. The data represents the mean ingrowth for several dogs sacrificed between 10 and 38 weeks ( 3 square-wave animals, 2 ramp-wave animals).

(2) There was a statistically significant difference in the remodeling response at platen locations 1 and 5 when compared to locations 2,3, and 4. Platens 1 and 5 correspond to the condyle regions of the distal femoral metaphysis. The results suggest that equilibrium morphology is dependent on initial morphology and loading conditions, or that these regions haven't reached equilibrium by 38 weeks. In general, these two regions of bone (pooled 1.5) were less oriented (more isotropic) and more connected when compared to pooled regions $2,3,4$ $(p<0.01)$.

(3) There was a statistically significant decrease in connectivity in the remodeling trabecular bone when compared to the contralateral specimens (with or without adjusting for location effects). This finding is consistent with the transition from a region which must withstand multiaxial stresses to a condition where experimental load is delivered along one axis $(p<0.005)$.

(4) There were significant relationships between loading magnitude, and bone volume fraction, trabecular plate thickness, and trabecular plate separation $(p<0.005)$. The correlation coefficients varied from different platen locations, however, not allowing us to derive a general relationship. This interaction may have resulted from our limited sample size, or it may suggest the importance of initial conditions.

(5) There was a statistically significant increase in the degree of trabecular orientation when comparing the experimental specimens to their contralateral controls $(p<0.001)$. There was not a significant alteration in the direction of trabecular orientation (variance was high). This finding correlates well with the decrease in connectivity which would increase the percentage of existing trabeculae oriented towards the platen. This finding would tend to support the trajectorial theory since it is likely that the retained trabeculae were those that were aligned along the principal axes of compressive stresses at the platen interface. As is illustrated in Fig. 11. the change in stress trajectories induced by the implant resulted in a corresponding architectural reorientation.

\section{Finite Element Results}

For each of the nine animals, three stressmorphology relationships were examined. The first was the relationship between the contralateral limb morphology and the control analysis stress predictions. The second relationship examined was that of the change in morphology (the difference between contralateral and experimental limb morphology). versus the change in stress between the initial and control analysis. This relationship essentially measures how much subsequent changes in bone morphology correlate with changes in stress state between the normal gait loading and the experimental implant loading. Finally, the relationship between stress state and morphology at sacrifice was assessed. For all relationships the morphological parameters from the microcomputed tomography data were correlated to the stress and strain measures of Von Mises stress and Strain Energy Density (SED).

In general, the results from the control model revealed significant correlations between the morphological parameters and SED and Von Mises stress. The best correlations were with trabecular plate number. When all data from the nine animals were pooled (representing normal dog stress morphology relationships) only Von Mises stress and trabecular plate number were correlated $(p<0.001$, correlation coefficient $=0.71$ ) However, as is illustrated in Fig. 12, the data forms clusters, suggesting that the continuum estimates of stress and archilecture may be insufficient to account for the complex local architecture. This may also reflect inadequate assumptions about the parameters used to model the normal loading history to the control canine distal femur.

In experimental animals subjected to square waveform loading significant correlations were found between the change in stress parameters and the change in morphology measures. These correlations improved with time, suggesting that the bone is moving towards equilibrium. As illustrated (Fig. 13) the correlation coefficients between Von Mises stress and connectivity. volume fraction, and surface to volume ratio are dependent on time. This figure 

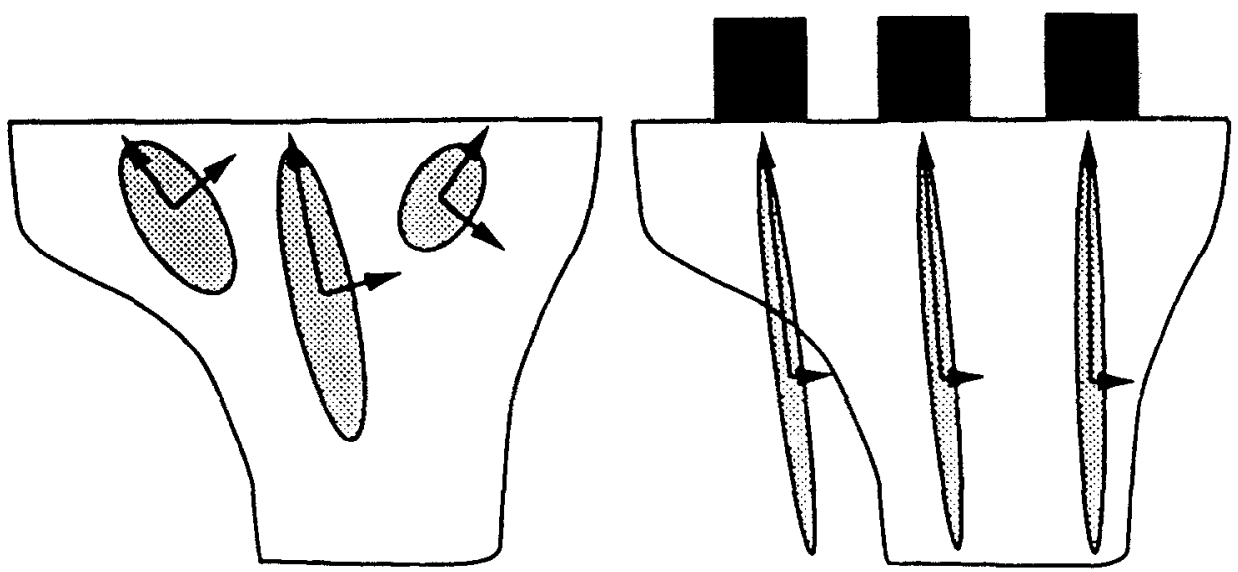

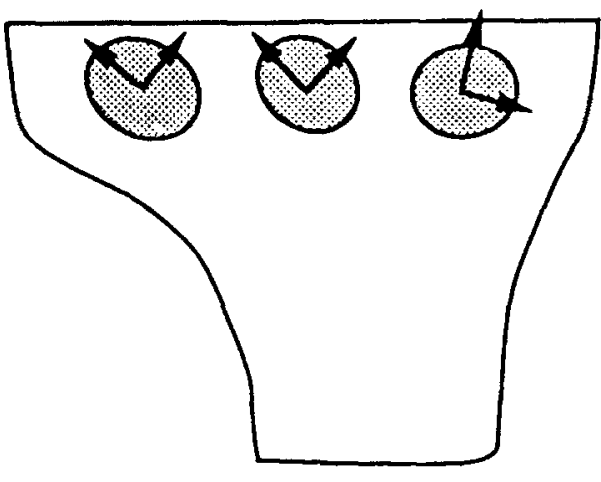

Control bone orientation

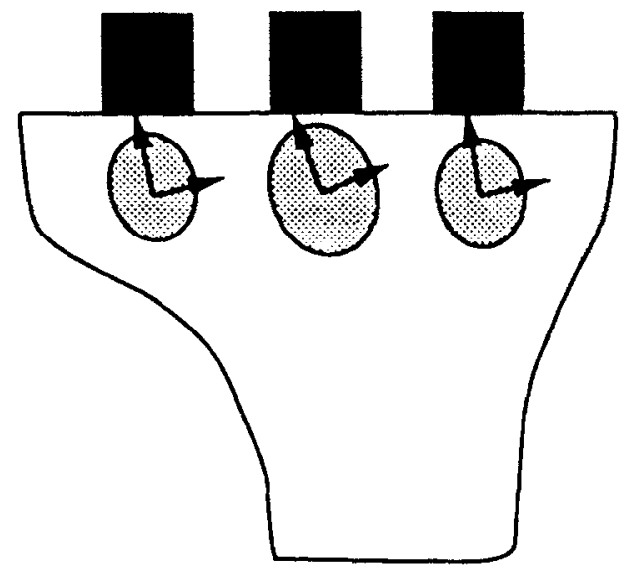

Experimental bone orientation

Fig. 11. A representative analysis of continuum stress orientation and trabecular bone orientation is illustrated for the 38 week squarewave animal. The aspect ratio of the stress ellipse represents the ratio of principal stresses in each coordinate direction. while the orientation of the ellipse corresponds to the stress orientations relative to the platens. The trabecular anisotropy is represented by the mean intercept length analysis of the bone regions. Platen regions 1.2.3 are illustrated along with their contralateral control stress estimates (normal articulation) and architectural measures.

also suggests that the rate of response for certain morphologic adaptations differs. In contrast to these findings, no correlations were found between stress measures and morphology for the slow rise time animals (Fig. 14).

\section{DISCUSSION}

The purpose of this study was to evaluate an experimental model designed to document the response of trabecular bone to implant induced controlled load. It was not the intention of this study to exhaustively evaluate the many parameters which may influence trabecular bone adaptation but rather to characterize the efficacy of the experimental model and survey the response to a limited number of physiologically relevant parameters.
The results of the experiment indicate that significant trabecular bone remodeling can be induced by the activated implant. The consistency of the results at the five locations within each animal support this finding. Similarly, the statistically significant reduction in connectivity and increased degree of trabecular orientation at the bone platen interface further support the use of the model.

The most striking results of this study came from the comparison of the response to the slow rise wave form and the fast or square wave form. As noted, under the ramp stimulation a normal trabeculation pattern was maintained but with inconsistent ingrowth. Dramatic remodeling response under conditions of the square wave form was marked by significant ingrowth and "corticalization" of the adjacent bone. The bone had a woven appearance suggestive of a fracture response and was similar to the reported histologic features of retrieved ingrowth 


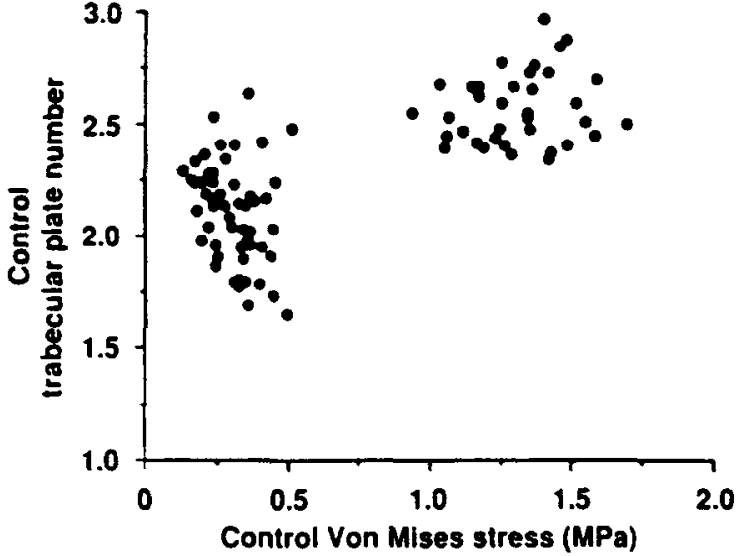

Fig. 12. The relationship between Von Mises stress and trabecular plate number for models representing normal canine femurs under normal knee articulating loads is demonstrated. The graph represents the pooled data for all nine animals. Note the data clusiers. suggesting the limitations of the continuum modeling efforts.

prostheses discussed by previous investigators (Spector. 1988: Brunski, 1988: Carter, 1988; Sevitt, 1981; Cook et al. 1988: Jasty, 1987; Cheal et al., 1987). The analysis of correlations between measures of trabecular adaptation and predictions of induced stress and strain fields were only significant under the fast rise time condition while no correlations were found for the slow rise time. One explanation for these findings may be related to the analytical modeling procedures which are based on continuum assumptions. For this model, the continuum stress state underneath the platens is nearly statically determinant. Thus, the continuum stress state changes little, even for large changes in material properties resulting from changes in architecture. The observation of the intense localized remodeling response which was similarly observed in the

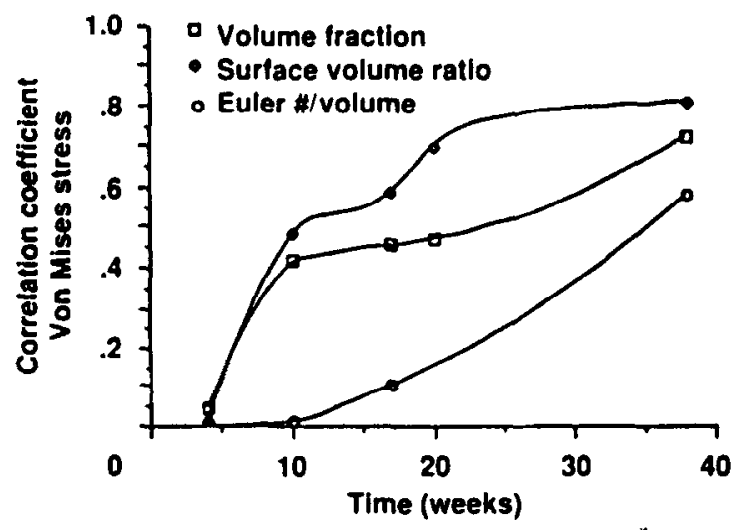

Fig. 13. Correlation between Von Mises stress and morphology versus time: square wave. The correlation coefficients between changes in Von Mises stress due to the implant and changes in trabecular morphology (reflecting adaptation) are plotted as a function of time for the squarewave animals. It is clear that the correlations improve with longer term animals suggesting progression towards an equilibrium state.

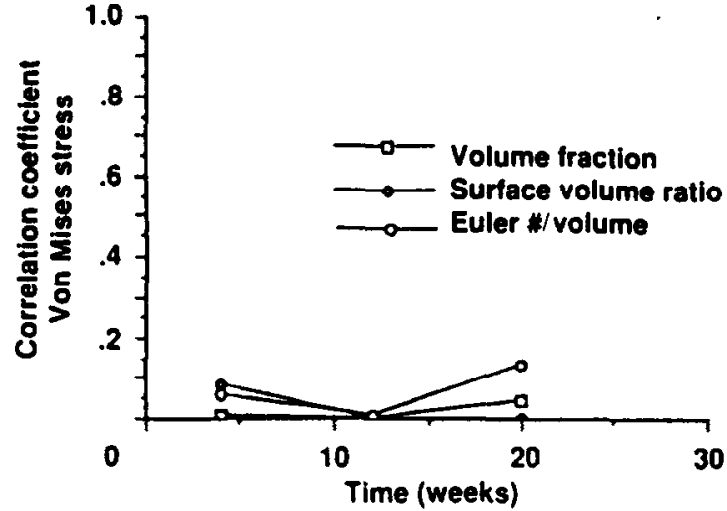

Fig. 14. Correlation between Von Mises stress and morphology versus time: ramp wave. No significant correlations were found between calculations of Von Mises stresses and trabecular adaptation under ramp waveform stimulation.

experimental studies of Cheal ef al. (1987) implies that microstructural modeling techniques are needed to more accurately predict the stress and strain fields induced at the bone implant interface. In a preliminary study reported by Hollister et al. (1990) microstructural analysis using homogenization theory of these experimental results provided significantly improved correlations (particularly in strain measures) for the square wave stimulation. This analysis, which was able to account for the architectural adaptation, continued to find no correlations between stimulation and adaptation for the slow rise time wave form. These results, therefore, support the concept that modeling/remodeling activity follows a structurally optimized scheme. The slow wave form stimulus was sufficient to maintain the majority of the bone structure but not to cause remodeling of bone. In contrast, the fast rise time stimulation induced large perturbations from the homeostatic stress states in the trabecular bone which lead to a significant adaptation response. The response subsequently lead to a structurally optimized architecture as inferred by the excel lent correlations with stress and strain field predictions. These observations support the concept of a remodeling "dead" zone discussed by Carter, 1984; Huiskes et al., 1987; Beaupre et al., 1989.

An additional possible explanation for the different response under the different rates may be related to rate effects resulting from transient dynamic stresses. In preliminary experimental work in our laboratory. subjecting an $8 \mathrm{~mm}$ cube of trabecular bone to a $70 \mathrm{~ms}$ rise time squarewave showed an initial spike in which the force at the platen bone interface measured using a piezoelectirc load cell may be up to twice the equilibrium load produced by the hydraulic fluid pressure. Thus, the force at the platen bone interface may be instantaneously much greater for the fast rise waveform than for the slow waveform causing more localized damage leading to a fracture type response. However, dynamic finite element analysis of a linear elastic platen model showed little stress 
amplification due to dynamic loading. The rate effects, therefore, may be due to the marrow within the bone pores. As noted by Carter and Hayes (1977). the marrow has little mechanical stiffening effect except at very high strain rates, consistent with the $70 \mathrm{~ms}$ rise time. Future microstructural analyses may need to include fluid affects to differentiate the different mechanical response to bone and marrow at different loading rates, and to confirm if more damage is accumulated at higher loading rates.

Finally, the correlation between mechanical stress and morphologic adaptation as noted in (Fig. 13) support the existence of a specific remodeling strategy in response to significant implant interface stimulation. The data suggests that the first response to mechanical stimulation is a significant increase in bone deposition (correlations with bone volume fraction and surface to volume ratio) followed by a secondary reorganizational phase (correlations with connectivity). These observations further support the similarity of the response to fracture healing processes.

In summary, we believe we have developed an experimental model which enables the investigation of trabecular bone adaptation to controlled implant induced mechanical stimulation. Significant remodeling responses were correlated with the characteristics of the loading wave forms and responses were found to be consistent across the five sampled locations within each experimental animal. The results support the need for continued development in modeling techniques based on microstructural analysis to account for localized response near the implant bone interface. Finally, the control of loading boundary conditions provided by the implant coupled with histologic features similar to those observed in other human and animal implant studics support the continued use of the model for evaluating trabecular bone adaptation under experimentally controlled mechanical conditions.

Acknowledgements - This study was supported in part by a grant from the National Institutes of Health (AR31793). This study would not have been possible without the significant contributions of Dennis Kayner, Kathy Sweet. Robert Goulet. Karl Jepsen, Fred Champlain and David Viviano. In addition, the authors acknowledge the statistical consultation provided by Dr. Morton Brown of the Department of Biostatistics.

\section{REFERENCES}

Beaupre. G. S., Caner, D. R., Fyhrie. D. P. and Orr, T. E. (1989) A bone surface area controlled time-dependent theory for remodeling. Trans. Orthop. Res. Soc, 14. 311.

Binderman, I., Zor, U., Kaye, A. M., Shimshoni. Z., Harell. A., and Somjen, D. (1988) The transduction of mechanical force into biochemical events in bone cells may involve activation of phospholipase $A_{2}$. Calcif. Tissue Int. 42, 61-266.

Brunski. J. B. (1988) The influence of force, motion. and related quantities on the response of bone to implants. In: NonCemented Total Hip Arthroplast (Edited by Fitzgerald. R.H.), Raven Press. New York.

Burr, D. B., Martin, R. B.. Schaffler, M. B., and Radin, E. L. (1985) Bone remodeling in response to in vivo fatigue microdamage. J. Biomechanics 18, 189-200.
Canter. D. R.. Fyhric. D. P., and Whalen. R. T. (1987) Trabecular bone density and loading history: regulation of connective tissue biology by mechanical energy. J. Biomechanics 20(8). 785-794.

Carter. D. R. (1988) The cemented acetabular component: biomechanics and skeletal adaptation. In: Non-Cemented Total Hip Arthroplasty. (Edited by Fitzgerald. R.H.). Raven Press. New York.

Carter. D. R. (1982) The relationship between in vivo strains and cortical bone remodeling. Cris. Rev. Biomed. Eng. 8. 1-28.

Carter. D. R. (1984) Mechanical loading histories and cortical bone remodeling. Calcif. Tissue Int. 36. S19.S24.

Chamay. A. and Tschantz. P. (1972) Mechanical influences in bone remodeling. Experimental Research on Wolffs Law. J. Biomechanics 5. 173-180.

Cheal. E. J., Hayes. W. C.. Leuzinger, R. A., and Nunamaker, D. M. (1985) A model for trabecular bone remodeling around an implant. Trans. Ortitop. Res. Soc. 10. 376.

Cheal. E. J.. Snyder. B. D.. Nunamker. D. M., and Hayes, W. C. (1987) Trabecular bone remodeling around smooth and porous implants in an equine patellar model. J. Biomechanics 20(11). $1121-1134$.

Churches, A. E.. Howlett. C. R.. Waldron. K. S.. and Ward. G. W. (1979) The response of living bone to controlled time varying loading: method and preliminary results. J. Bismechanics 12.35-34.

Cook. S. D., Thomas. K. A.. and Haddad. R. J. (1988) Histologic anaiysis of retrieved human porous-coated total joint components. Clin. Orthop. 234, 90.

Cowin. S. C. (1985) The relationship between the elasticity tensor and the fabric tensor. Mech. Mater. 4. 137-147.

Cowin. S. C. (1986) Wolfr's law of trabecular architecture at remodeling equilibrium. J. Biomech. Eng. 108. 83-88.

Culmann. C. (1866) Die Graphische Statik. 1. Auflage. Zurich, Mayer und Zeller.

Feldkamp, L. A., Goldstein, S. A., Parfitt, A. M., Jesion, G., and Kleerekoper, M. (1989) The direct examination of three dimensional bone architecture in vitro by computed tomography. S. Bone Miner. Res, 4(1), 3-11.

Firoozbakhsh. R. and Cowin, S. C. (1980) Devolution of inhomogeneities in bone structure: predictions of adaptive elasticity theory. J. Biomech. Eng. 102, 287-293.

Frost, H. M. (1983) A determinant of bone architecture: the minimum effective strain. Clin. Orthop. 175, 286-292.

Frost. H. M. (1964) The Laws of Bone Structure. Springfield, Charles $C$. Thomas.

Frost. H. M. (1983) The regional acceleratory phenomena. Henry Ford Hospiral Medical Journal 31. 3-9.

Fyhrie, D. P. and Canter. D. R. (1986) A unifying principle relating stress to trabecular morphology. J. Orthop. Res. 4 , 304-317.

Fyhrie. D. P. and Carter, D. R. (1990) Femoral head apparent density distribution predicted from bone stress. J. Biomechanics 23, 1-10.

Goodship. A. E.. Lanyon. L. E., and McFie. H. (1979) Functional adaptation of bone to increased stress. J. Bone Joins Surg. 61A. 539-546.

Harell, A.. Dekel. S., and Vinderman. I. (1977) Biochemical effect of mechanical stress on cultured bone cells. Calcif. Tissue Res. (suppl) 22, 202-209..

Harrigan, T. P. and Mann, R. W. (1984) Characterization of microstructural anisotropy in orthotropic materials using a second rank tensor. J. Mater. Sci. 19, $761-767$.

Hart. R. T.. Davy, D. T., and Heiple, K. G. (1984) Mathematical modeling and numerical solutions for functionally dependent bone remodeling. Calcif. Tissue Imt. 36. 5104-5109. 
Hassler. C. R., Rybicki, E. F. Simon. F. A., and Weis, E. B. (1974) Measurements of healing an osteotomy in a rabbit calvarium: the influence of applied compressive stress on collagen synthesis and calcification. J. Biomechanics 7. 545-550.

Hayes. W. C. and Snyder. B. (1981) Toward a quantitative formulation of Wolff s law in trabecular bone in mechanical properties of bone. ASME 45, 43-68.

Heck. D. (1988) Personal Communication.

Hegedus. D. H. and Cowin. S. C. (1976) Bone remodeling t: a theory of adaptive elasticity. J. Elast. 6(4). 313-326.

Hert. J.. Pribylova, E., and Liskova. M. (1972) Reaction of bone to mechanical stimuli. Acta Anat. 82. 218-230.

Hollister, S. J.. Goldstein. S. A., Jepsen, K. J., and Goulet. R. W. (1990) Continuum and microstructural stress morphology relationships for trabecular bone subject to controlled impant loads. Trants. Orthop. Res. Soc. 15. 74.

Huiskes, R., Weinans, H., Grootenboer, H. S., Dalstra, M., Fudula, B., and Slott. T. J. (1987) Adaptive bone remodeling theory applied to prosthetic design analysis.J. Biomechanics 20(11). $1335-1150$.

Jasty. M.. Sumner. R.. Galante, J. O., Bragdon, C. R.. Cargill, E. A., and Harris. W. H. (1988) Bone ingrowth into poroussurfaced Harris/Galante prosthesis acetabular components retrieved from human patients. 55th AAOS Annual Meeting. Allanta, Feb.

Kimmel. D. B. (1986) A discrete event simulation of the adult trabecular skeleton. Math. Modeling 7. 957-980.

Klein-Nulend, J.. Veldhuijzen. J. P.. deLong. M., and Burger, E. H. (1987) Increased bone formation and decreased bone resorption in fetal mouse calvaria as a result of intermittent compressive foree in vitro. Bone Mineral 2. 441-448.

Kuhn, J. L., Goldstein. S. A., Feldkamp. L. A., Goulet. R. W. Jesion. G.. and Matthews, L. S. (1990) Evaluation of a microcomputed tomography system to study trabecular bone structure. J. Orthop. Res.. (in press).

Kuhn, J. L., Goulet, R., Pappas, M., and Goldstein, S. A. (1990) Morphometric and anisotropic symmetries of the canine distal femur. J. Orthop. Res. 8(5), 776-780.

Lanyon, L. E. and Baggott. D. G. (1976) Mechanical function as an influence on the structure and form of bone. J. Bone Joint Surg. 58B. 436-443.

Lonyon, L. E. (1974) Experimental suppon for the trajectorial theory of bone structure. J. Bone Joint Surg. 56B, 160-166.

Lanyon, L. E. (1987) Functional strain in bone tissue as an objective and controlling stimulus for adaptive bone remodcling. J. Biomechanics 20(11/12), 1083-1094.
Liskova M. and Hert. J. (1971) Reaction of bone to mechanical stimuli. Part 2: periosteal and endosteal reaction of tibial diaphysis in rabbit to intermittent loading. Fabia Morph. 19, 301-317.

Marin. R. B. and Burr. D. B. (1982) A hypothetical mechanism for the stimulation of osteonal remadeling by fatigue damage. J. Biomechanics 15, 137-139.

Parfitt. A. M. (1984) The cellular basis of bone remodeling: the quantum concept reexamined in light of recent advances in the cell biology of bone. Calcif. Tissue Int. 36. 537-545.

Parfitt. A. M. (1979) The quantum concept of bone remodeling and turnover. Indications for the pathogenesis of osteoporosis. Calcif. Tissue Int. 28. 1-5.

Pollack, S. R.. Salzstein, R., and Pienkowski, D. (1984) The electric double layer in bone and its influence on stress generated potentials. Calcif. Tissue Int. 36. 577.581.

Pollard, A. W., Feik, S. A., and Storey (1984) Remodeling of bone and bones: effects of translation and strain of tansplants. Br. J. Exp. Pathol. 65, 655-670.

Radin, E. L., Pugh. J. W., Steinberg, R. S, Parker, H. G., and Roc, R. M. (1972) Trabecular microfractures in response to stress: the possible mechanism of Wolfrs law. International Congress Series \#291. Orthop. Surg. and Trauma.. 59-65.

Rodan, G. A. Thomas, M., and Alan. H. (1975) A quantitative method for the application of compressive forces to bone in tissue culture. Calcif. Tissue Res. 18, 125-131.

Rubin. C. T. and Lanyon. L. E. (1984) Regulation of bone formation by applied dynamic loads. J. Bone Joint Surg. 66A. 397-402.

Seireg. A. and Kempke, W. (1969) Behavior of in vivo bone under cyclic loading. J. Biomechanics 2. 455-461.

Sevitt, S. (1981) Bone repair and fracture healing in man. Churchill Livingstone, Edinburgh.

Skerry, T. M., Pitensky, L., Chayen. J., and Lanyon, L. E. (1987) Strain memory in bone tissue: is proteoglycan-based persistence of strain history a cue for the control of adaptive bone remodeling? Trans. Orthop. Res. Soc. 12, 75 .

Spector, M. (1988) Current concepts of bony ingrowth and remodeling. In: Non-Cemented Total Hip Arthroplasty (Edited by Fitzgerald, R.H.), Raven Press. New York.

Stone, J. L.. Snyder, B. D., Hayes, W. C., and Strang, G. L. (1984) Three-dimensional stress morphology analysis of trabecular bone. Trans, of the 30th Orhop. Res. Soc.9. 199.

VonMeyer, G. H. (1867) Die Architektur der Spongiosa. Arch. Anat. Physial. Wissenhaftliche Med. (Reichert und DuboisReymonds Archiv), 34, 615-628.

Wolff. J. (1892) Das Gaesetz der Transformation der Knochen. Berlin. A., Hirchwild. 